09

\title{
Люминесцентные свойства углеродных наноточек на поверхности сферического микрорезонатора
}

\author{
( Д.А. Еуров, Е.Ю. Стовпяга, Д.А. Курдюков, А.А. Дукин , А.Н. Смирнов, В.Г. Голубев \\ Физико-технический институт им. А.Ф. Иофрфе РАН, \\ Санкт-Петербург, Россия \\ ฯ E-mail: dookin@gvg.ioffe.ru
}

Поступила в Редакцию 29 апреля 2020 г.

В окончательной редакции 29 апреля 2020 г.

Принята к публикации 5 мая 2020 г.

\begin{abstract}
Синтезированы гибридные структуры из монодисперсных сферических частиц кремнезема, являющихся сферическими микрорезонаторами, и излучающих углеродных наноточек на их поверхности. Углеродные наноточки присоединены к поверхности частиц посредством контролируемой коагуляции в трех растворителях: аммиак, соляная кислота и глицерин. В спектрах фотолюминесценции гибридных структур во всем диапазоне длин волн излучения углеродных наноточек от УФ до ближнего ИК наблюдались интенсивные узкие линии, связанные с излучением наноточек в модах шепчущей галереи сферического микрорезонатора. Из сопоставления с расчетом спектральных положений мод шепчущей галереи, выполненным методом матриц переноса сферических волн, идентифицированы все наблюдаемые линии.
\end{abstract}

Ключевые слова: монодисперсные сферические частицы кремнезема, углеродные наноточки, фотолюминесценция, моды шепчущей галереи.

DOI: 10.21883/FTT.2020.10.49922.102

\section{1. Введение}

Углеродные наноточки (УТ, c-dots) представляют собой недавно открытый вид углеродных материалов, который включает дискретные квазисферические частицы с типичными размерами менее $10 \mathrm{~nm}$. Различным методам получения, исследованию уникальных физикохимических свойств и перспективам разнообразных применений УТ посвящено большое количество обзоров (см., например, недавние [1-4]).

К настоящему моменту предложены технологичные, быстрые и недорогие методы синтеза УТ. Возможность функционализации поверхности различными органическими, неорганическими или биологическими лигандами позволяет целенаправленно изменять их свойства и расширяет области планируемых применений. В сравнении с полупроводниковыми квантовыми точками люминесцентные УТ обладают рядом преимуществ, которые особенно важны для биологических и медицинских применений. К ним относятся биосовместимость, малая токсичность, химическая инертность, растворимость в воде и фотостабильность. Наибольший интерес проявляется к исследованиям оптических свойств УТ, так как в основе многих их применений лежат люминесцентные свойства (см. обзоры [5-7]).

В настоящей работе с целью усиления интенсивности и получения узких спектральных линий излучения УТ созданы гибридные структуры, состоящие из монодисперсных сферических частиц кремнезема (МСЧК) с прикрепленными к их поверхности люминесцентными УТ. Данный подход был использован ранее для получения гибридных структур, в которых со сферическими микро- частицами связывались квантовые точки [8-12], Ј-агрегаты [13], $\mathrm{MoS}_{2}$ [14], нанокристаллы алмазов с центрами окраски $[15,16]$. Сферические микрочастицы в таких структурах выполняли роль оптических микрорезонаторов (MP) с модами шепчущей галереи (МШГ, WGM).

Сферические оптические микрорезонаторы с МШГ характеризуются высокой добротностью в широким диапазоне длин волн и малым эффективным объемом локализации фотонных мод. МШГ распространяются в узком кольце у поверхности МР, испытывая полное внутреннее отражение от границы сферически-симметричного диэлектрического тела $[17,18]$. Электромагнитное поле МШГ локализовано вблизи поверхности МР и частично проникает за пределы МР в окружающее пространство $[19,20]$, что оказывает влияние на спонтанную эмиссию светоизлучающих частиц, нанесенных на поверхность МР. Расстояние, на которое эванесцентное поле проникает за пределы МР, обратно пропорционально показателю преломления вещества МР. За счет взаимодействия эванесцентного электромагнитного поля МШГ с электронными возбуждениями светоизлучающих частиц в спектре спонтанной эмиссии частиц возникает серия узких пиков, положение которых совпадает с модами шепчущей галереи MP.

\section{2. Получение гибридных структур МСЧК-УТ}

\section{1. Синтез монодисперсных сферических частиц кремнезема}

Монодисперсные сферические частицы кремнезема (МСЧК, микросферы $a-\mathrm{SiO}_{2}$ ) диаметром $3.5 \pm 0.15 \mu \mathrm{m}$ 
синтезировались с использованием методики, описанной в работах $[21,22]$ путем гидролиза тетраэтоксисилана (ТЭОС) в спирто-водно-аммиачной среде. На первом этапе были получены МСЧК диаметром $700 \pm 25 \mathrm{~nm}$. Мольное соотношение реагентов в реакционной смеси ТЭОС : $\mathrm{NH}_{3}: \mathrm{H}_{2} \mathrm{O}: \mathrm{C}_{2} \mathrm{H}_{5} \mathrm{OH}-1: 15: 50: 72$. На следующем этапе проводилась процедура „доращивания“ частиц [22]. В реакционную смесь $\mathrm{NH}_{3}: \mathrm{H}_{2} \mathrm{O}: \mathrm{C}_{2} \mathrm{H}_{5} \mathrm{OH}$ (мольное соотношение реагентов $30: 50: 72$, соответственно) объемом 11 , содержащую $1 \mathrm{~g}$ МСЧК размером $700 \mathrm{~nm}$, каждые $10 \mathrm{~min}$ добавляли по $5 \mathrm{~g}$ ТЭОС. Получаемые продукты гидролиза ТЭОС конденсировались вблизи поверхности субмикронных частиц, покрывая их слоем гидратированного $a-\mathrm{SiO}_{2}$ и осуществляя тем самым дальнейший рост. Для получения частиц диаметром $3.5 \mu \mathrm{m}$ в реакционную смесь всего было добавлено $425 \mathrm{~g}$ ТЭОС. Затем синтезированные частицы отжигались при $500^{\circ} \mathrm{C}$.

\section{2. Синтез углеродных наноточек}

Монодисперсные УТ синтезировали методом термического разложения 3-аминопропилтриэтоксисилана (АПТЭС) в порах темплата [23,24]. В качестве темплата были использованы синтезированные согласно разработанной нами методике $[25,26]$ мезопористые МСЧК диаметром $500 \pm 20 \mathrm{~nm}$, имеющие внутреннюю систему цилиндрических наноканалов (нанопор) одинакового диаметра $(3.1 \pm 0.5 \mathrm{~nm})$. Мезопористые МСЧК пропитывались 50\% mass. спиртовым раствором АПТЭС, затем отжигались на воздухе при $250^{\circ} \mathrm{C}$. Материал темплата $\left(a-\mathrm{SiO}_{2}\right)$ селективно вытравливался в $40 \% \mathrm{vol}$. HF. Для очистки от продуктов растворения $\mathrm{SiO}_{2}$ осадок, содержащий УТ, пять раз редиспергировался в деионизованной воде под действием ультразвука, а затем осаждался центрифугированием. По данным динамического светорассеяния, просвечивающей электронной микроскопии и атомно-силовой микроскопии размер УТ составлял $3.5 \pm 0.9 \mathrm{~nm}[23,24]$. Анализ результатов исследования УТ методами рентгеновской дифракции, рамановской спектроскопии, ИК-спектроскопии и исследования тонкой структуры спектров поглощения рентгеновского излучения вблизи края поглощения углерода C1s показал, что синтезированные УТ состоят из 7-10 дефектных графеновых слоев, покрытых, преимущественно, кислородсодержащими группами (гидроксильными, карбонильными, карбоксильными) [24].

\section{3. Связывание УТ с поверхностью МСЧК}

Поверхность микросфер $a-\mathrm{SiO}_{2}$ покрывалась наноточками посредством контролируемой коагуляции УТ и МСЧК в трех разных растворителях. Для этого навеска МСЧК заливалась коллоидным раствором УТ в концентрированном растворе аммиака $\mathrm{NH}_{3} \cdot \mathrm{H}_{2} \mathrm{O}$, глицерине или концентрированной $\mathrm{HCl}$, подвергалась ультразвуковой обработке и хранилась в закрытом контейнере в течение суток. В это время происходила коагуляция частиц, в результате которой УТ связывались с поверхностью МСЧК посредством сил Ван-дер-Ваальса, что позволяло углеродным наноточкам оставаться на поверхности частиц кремнезема после проведенной далее процедуры высушивания. Затем смесь выдерживалась при температуре приблизительно $120^{\circ} \mathrm{C}$ в течение $20 \mathrm{~min}$, после чего МСЧК, содержащие на поверхности УТ, редиспергировались в деионизованной воде при помощи ультразвука. Образцы, полученные совместной коагуляцией УТ и МСЧК в $\mathrm{NH}_{3} \cdot \mathrm{H}_{2} \mathrm{O}$, глицерине и $\mathrm{HCl}$ обозначены, соответственно, S59, S60 и S61.

Выбор растворителей обусловлен различием поверхностного заряда растворенных в них МСЧК и УТ. В водном растворе аммиака дзета-потенциал углеродных наноточек равен $-45 \mathrm{mV}$ [24], а микросфер $a-\mathrm{SiO}_{2}-$ $-80 \mathrm{mV}$ [27]. В таких условиях как гидрозоль УТ, так и гидрозоль МСЧК агрегативно устойчивы. Из теории Дерягина-Ландау-Фервея-Овербека известно, что маленькие частицы в присутствии больших нестабильны. В результате в гидрозоле МСЧК + УТ индивидуальные углеродные наноточки связываются с поверхностью частиц кремнезема. При сушке раствор становится более концентрированным, поэтому УТ становятся еще менее агрегативно устойчивыми. В силу большего одноименного поверхностного заряда МСЧК, по сравнению с УТ, последние преимущественно слипаются друг с другом. В результате в концентрированном растворе с МСЧК коагулируют не индивидуальные УТ, а их агрегаты, и поэтому концентрация индивидуальных УТ на поверхности микросфер $a-\mathrm{SiO}_{2}$, вероятно, относительно невысока.

При использовании глицерина среду можно считать нейтральной. При $\mathrm{pH} \sim 7$ дзета потенциал МСЧК снижается по абсолютному значению с -80 до $-40 \mathrm{mV}$ [27], а дзета потенциал УТ по-прежнему составляет порядка $-40 \mathrm{mV}$ [24]. В результате индивидуальные УТ, по-видимому, более склонны к коагуляции с крупными МСЧК, чем между собой. Кроме того, глицерин имеет бо́льшую вязкость и температуру кипения по сравнению с раствором $\mathrm{NH}_{3}$, что замедляет процесс высушивания. Поэтому при коагуляции частиц в глицерине между ними могут оставаться прослойки растворителя. Это приводит к тому, что даже при коагуляции гипотетически образуемых агрегатов УТ с частицами кремнезема непосредственного контакта между УТ нет. На финальном этапе сушки прослойка глицерина разрушается, что приводит к контакту УТ и МСЧК. При этом соседние УТ могут не касаться друг друга. Таким образом, при использовании глицерина на поверхности микросфер $a-\mathrm{SiO}_{2}$ после высушивания находятся преимущественно индивидуальные УТ.

В кислой среде (раствор $\mathrm{HCl}$ ) дзета потенциал как для МСЧК, так и для УТ снижается по абсолютной величине, меняет свой знак и становится равным $+10 \mathrm{mV}$ [27] и $+20 \mathrm{mV}$ [24] соответственно. В этих условиях агрегативная устойчивость УТ в суспензии снижается. Углеродные наноточки изначально находятся 
в растворе частично в виде агрегатов, кроме того, возможна коагуляция МСЧК в силу малого электростатического отталкивания. В результате после нанесения УТ на поверхность МСЧК наноточки, по-видимому, оказываются преимущественно в виде агрегатов.

\section{3. Результаты и обсуждение}

Решения уравнений Максвелла для диэлектрического шара в однородной диэлектрической среде в виде сферических волн - моды диэлектрического шара приведены в $[28,29]$. Эти решения имеют асимптотику в виде убегающей на бесконечности сферической волны и характеризуются тремя числами: полярным индексом $l$, азимутальным индексом $m$, и радиальным индексом $q$. Полярный индекс $l \geq 1$ (или номер моды в приближении волновой оптики) соответствует числу длин волн, укладывающихся на экваторе микросферы. Азимутальный индекс $m$ $(-l \leq m \leq l)$ описывает угловое распределение поля в меридиональном сечении микросферы $(l-m+1$ равно числу максимумов моды в меридиональном сечении). Радиальный индекс $q$ соответствует числу максимумов моды, лежащих внутри шара по радиусу. Для идеально сферического шара частоты мод не зависят от $m$, т.е. моды кратно вырождены по $m$. В случае даже незначительных отклонений формы шара от сферической это вырождение снимается.

Моды шепчущей галереи - это подмножество мод диэлектрического шара, которые характеризуются тем, что для них $m=l$ или $m$ близко к $l$, а значение $q$ не превышает нескольких единиц. МШГ имеют поляризации ТЕ и ТМ. Моды ТЕ не имеют радиальной составляющей электрического поля, моды ТМ не имеют радиальной составляющей магнитного поля. В дальнейшем МШГ будут обозначаться как $\mathrm{TE}_{l}^{q}$ или $\mathrm{TM}_{l}^{q}$, где ТЕ или ТМ поляризации МШГ, $q$ и $l-$ соответствующие индексы.

Внутри шара поле МШГ прижато к поверхности в виде узкого кольца по экватору шара. Вне шара поле экспоненциально затухает на расстоянии $\lambda / 2 \pi\left(n^{2}-1\right)^{1 / 2}$, где $n$ - показатель преломления шара, $\lambda-$ длина волны [28]. Для сферических частиц $a-\mathrm{SiO}_{2}$, которые исследуются в данной работе, наименьшее значение этого расстояния равно приблизительно $50 \mathrm{~nm}$, что намного превышает диаметр углеродных наноточек. Таким образом, углеродная наноточка, прикрепленная к поверхности частицы, целиком находится в затухающем поле МШГ, и за счет этого она взаимодействует с МШГ.

В настоящей работе расчет длин волн, ширин и пространственного распределения поля МШГ для сферических частиц $a-\mathrm{SiO}_{2}$ проведен методом матриц переноса сферических волн [30]. При этом использованы разложение поля электромагнитной волны в базисе векторных сферических гармоник и условие непрерывности тангенциальных компонент электрического и магнитного поля на поверхности $a-\mathrm{SiO}_{2}$ микросферы. При расчете в

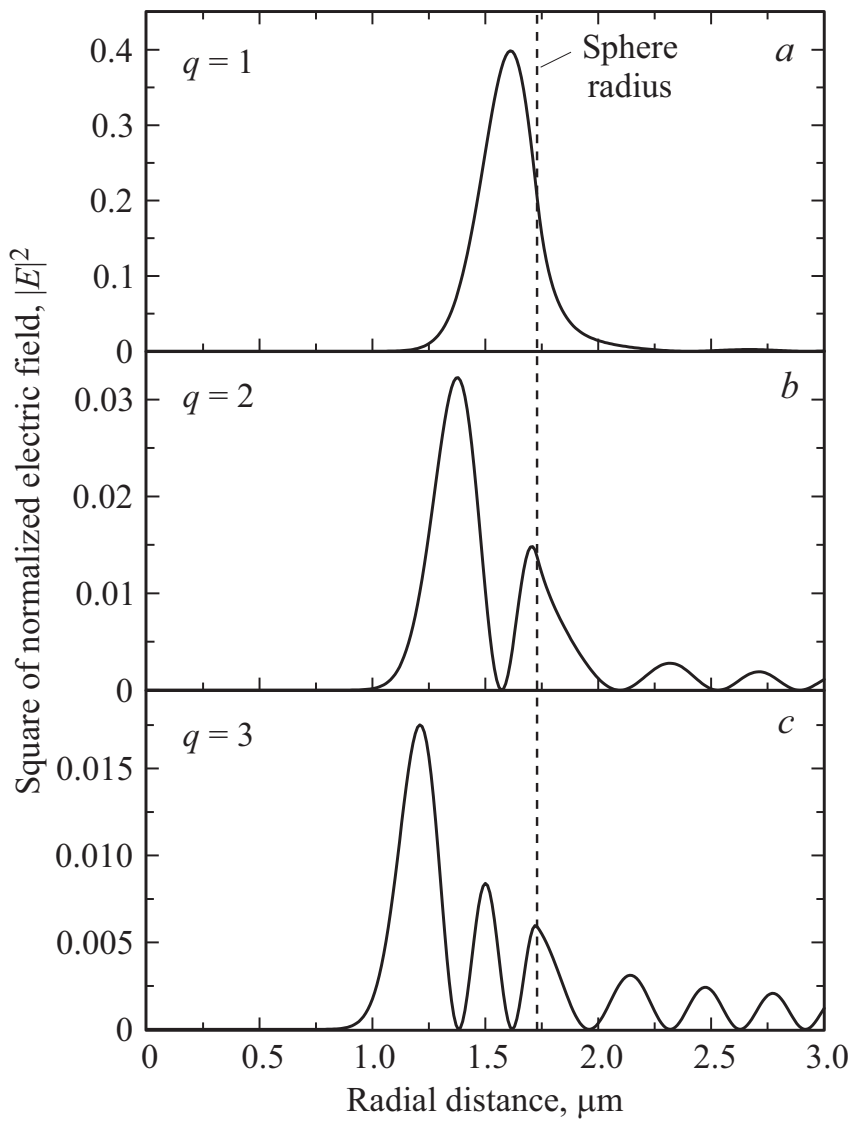

Рис. 1. Рассчитанное радиальное распределение квадрата модуля напряженности электрического поля мод шепчущей галереи $\mathrm{TE}_{21}^{1}(a), \mathrm{TE}_{21}^{2}(b), \mathrm{TE}_{21}^{3}(c)$. Диаметр $a-\mathrm{SiO}_{2}$ микросферы $3.46 \mu \mathrm{m}$.

качестве показателя преломления $a-\mathrm{SiO}_{2}$ использовался показатель преломления плавленого кварца с учетом зависимости его величины от длины волны [31]. При подгонке рассчитанных значений длин волн МШГ к полученным экспериментально, варьировался диаметр частицы $a-\mathrm{SiO}_{2}$.

На рис. 1 представлены рассчитанные распределения квадрата напряженности электрического поля для образца $\mathrm{S} 60$ (частица $a-\mathrm{SiO}_{2}$ диаметром $3.46 \mu \mathrm{m}$ ). Расчет проведен для трех ТЕ-поляризованных МШГ с одинаковым значением полярного индекса $l=21$ и с тремя радиальными индексами $q=1(a), q=2(b)$ и $q=3(c)$. Профили поля МШГ нормированы так, что амплитуда убегающей волны равна 1. Граница сферической частицы обозначена на рисунке вертикальной штриховой линией.

Эванесцентное поле МШГ выходит за границу $a-\mathrm{SiO}_{2}$ частицы приблизительно на $200 \mathrm{~nm}$ (рис. 1). Наноточки, прикрепленные к поверхности МСЧК, взаимодействуют с этим полем и излучают свет в МШГ. Интенсивность излучения наноточек в МШГ пропорциональна интенсивности электрического поля МШГ на поверхности МСЧК в месте расположения УТ, которая резко убывает с увеличением радиального индекса $q$. Кроме того, моды 


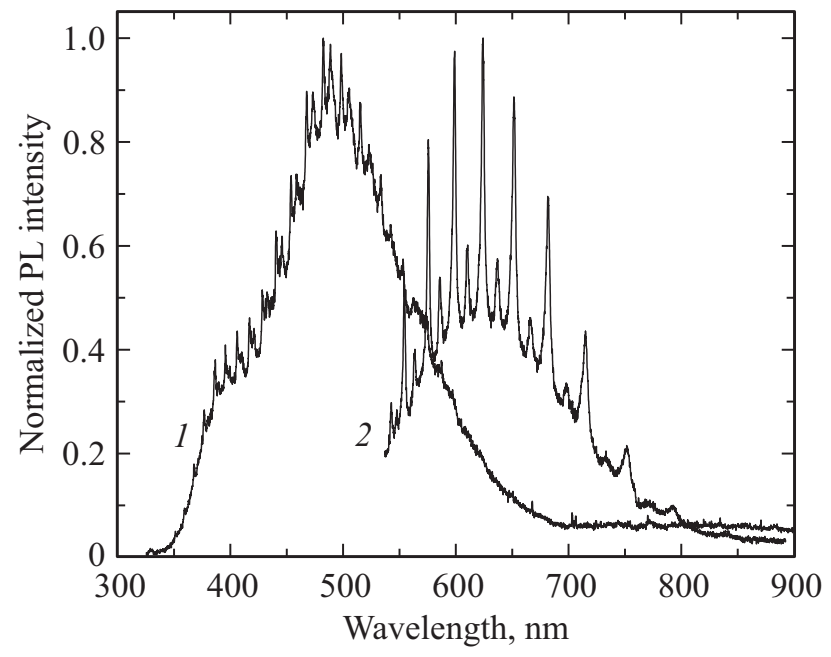

Рис. 2. Спектры ФЛ углеродных наноточек на поверхности одной МСЧК (образец S60) при длинах волн возбуждения $325 \mathrm{~nm}(1)$ и $532 \mathrm{~nm}$ (2). Спектры нормированы на максимум интенсивности.

с $q>1$ обладают низкой добротностью. Все вышеприведенные рассуждения также справедливы и для ТМ поляризованных МШГ.

На рис. 2 приведены спектры ФЛ (нормированные на максимум интенсивности спектров) одной МСЧК, покрытой углеродными наноточками (образец S60), при возбуждении Не-Cd лазером с $\lambda=325 \mathrm{~nm}$ (кривая 1) и $\mathrm{Nd}$ : YAG лазером с $\lambda=532 \mathrm{~nm}$ (кривая 2). Измерения спектров ФЛ проводились на спектрометре Horiba Jobin Yvon T64000, оснащенном конфокальным микроскопом [32].

Видно, что изменяя длину волны возбуждения ФЛ [33] оказывается возможным осушествить перекрытие широкого спектрального диапазона от УФ до ближнего ИК. В обоих спектрах на фоне широкой полосы (фоновой подставки) наблюдается структура, состоящая из пар узких пиков с большой и малой амплитудой. Как будет показано далее, эти пики могут быть идентифицированы как линии излучения углеродных наноточек в ТЕ- и ТМ-поляризованных МШГ сферической частицы $a-\mathrm{SiO}_{2}$. Распределение интенсивности пиков обусловлено спектральной зависимостью интенсивности сигнала ФЛ углеродных наноточек.

Значения отношения интенсивности пиков и фоновой подставки в спектре 2 в несколько раз больше, чем в спектре 1. Это можно объяснить разными условиями возбуждения ФЛ. При измерении спектра 2, луч $\mathrm{Nd}$ : YAG лазера фокусировался на выбранную точку на поверхности микросферы (на край микросферы) с помощью $100 \times$ объектива $(\mathrm{NA}=0.9)$ в пятно диаметром приблизительно $1 \mu \mathrm{m}$, что обеспечивало эффективное возбуждение МШГ [34]. При измерении спектра 1 использована ультрафиолетовая оптическая система. Луч $\mathrm{He}-\mathrm{Cd}$ лазера фокусировался на образец с помощью $40 \mathrm{NUV} \times$ объектива $(\mathrm{NA}=0.5)$ в пятно значительно большего размера, в результате чего его было сложно сфокусировать в заданную точку на поверхности микросферы и, таким образом, лазерное пятно могло освещать всю микросферу целиком. Такая фокусировка менее эффективна для возбуждения МШГ, в результате пики ФЛ, связанные с МшГ, имеют меньшую амплитуду относительно фоновой подставки. Поэтому далее мы будем анализировать спектры ФЛ углеродных наноточек, полученные при возбуждении лазером с длиной волны $532 \mathrm{~nm}$.

На рис. 3 представлены три спектра ФЛ углеродных наноточек, присоединенных разными способами к поверхности МСЧК. Связывание осуществлялось посредством контролируемой коагуляции в глицерине (кривая 1), $\mathrm{NH}_{3} \cdot \mathrm{H}_{2} \mathrm{O}$ (кривая 2) и $\mathrm{HCl}$ (кривая 3). В каждом спектре видна серия узких пиков большой амплитуды, между которыми расположены пики меньшей амплитуды. Спектральные положения и ширины пиков ФЛ для образцов S60 и S59 (кривые 1 и 2) близки между собой. Для образца S61 (кривая 3) спектральные положения пиков смещены по сравнению с положением пиков для образцов S60 и S59, а ширины пиков больше.

Расчет позволил подогнать значения рассчитанных длин волн МШГ под длины волн максимумов пиков



Рис. 3. Спектры ФЛ углеродных наноточек, присоединенных к поверхности МСЧК. Для удобства сравнения спектры сдвинуты по вертикали. Связывание УТ с поверхностью частицы осуществлялось посредством контролируемой коагуляции в глицерине, образец $\mathrm{S} 60$ (1); в $\mathrm{NH}_{3} \cdot \mathrm{H}_{2} \mathrm{O}$, образец $\mathrm{S} 59$ (2); в $\mathrm{HCl}$, образец S61 (3). Длина волны возбуждения $\lambda=532 \mathrm{~nm}$. Вертикальные штриховые линии показывают рассчитанные положения обозначенных МШГ. 


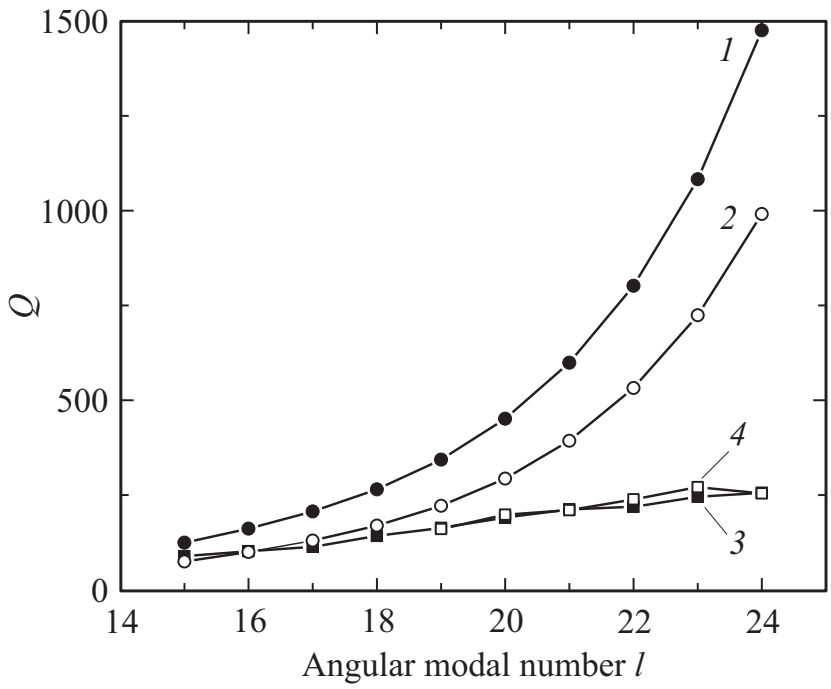

Рис. 4. Добротность ТЕ (1),(3) и ТМ (2), (4) поляризованных МШГ с радиальным индексом $q=1$, в зависимости от полярного индекса $l$. (1) и (2) - расчет, (3), (4) экспериментальная добротность пиков в спектре ФЛ образца S60 (кривая 1 на рис. 3). Сплошные линии проведены для наглядности.

в спектре ФЛ. Таким образом, все пики были идентифицированы как линии излучения УТ в МШГ. Также были определены поляризация, полярные и радиальные индексы соответствующих МШГ. Рассчитанные положения МШГ показаны на рис. 3 для спектров 1 и 3 вертикальными штриховыми линиями, рядом приведены обозначения соответствующих МШГ. Для спектра 2 они не показаны, поскольку очень близки к тем, что приведены для спектра 1. В результате подгонки определены значения диаметров частиц $a-\mathrm{SiO}_{2} \quad(D=3.46 \mu \mathrm{m}$ для $\mathrm{S} 60, D=3.47 \mu \mathrm{m}$ для $\mathrm{S} 59$ и $D=3.52 \mu \mathrm{m}$ для $\mathrm{S} 61)$. Таким образом, наблюдаемое смещение в длинноволновую область пиков ФЛ образца S61 (кривая 3) объясняется большим диаметром частицы. В спектрах на рис. 3 отсутствуют пики ФЛ, связанные с МШГ с радиальным индексом $q>1$, вследствие низкой добротности этих мод и менышей интенсивности электрического поля таких МШГ на поверхности частиц, где расположены углеродные наноточки (рис. 1).

На рис. 4 показана рассчитанная и экспериментальная добротность ТЕ и ТМ поляризованных МШГ (с радиальным индексом $q=1$ ), соответствующих пикам в экспериментальном спектре ФЛ (рис. 3, кривая 1) в зависимости от полярного индекса $l$. Теоретическое значение добротности определялось как $Q_{r}=\operatorname{Re}(\omega) / 2 \operatorname{Im}(\omega)$, где $\omega-$ комплексная частота МШГ, найденная методом матриц переноса [30]. Эта величина называется радиационной добротностью и связана с потерями, вызванными выходом волны за границу микросферы. Максимальное значение рассчитанной радиационной добротности МШГ в исследованном диапазоне полярных индексов $l \leq 24$ не превосходит 1500, что объясняется малым диаметром $a-\mathrm{SiO}_{2}$ микросферы равным $3.46 \mu \mathrm{m}$.

В экспериментальном спектре добротность МШГ определялась как $Q=\lambda / \Delta \lambda$, где $\lambda$ - длина волны пика, $\Delta \lambda$ - ширина пика на полувысоте. Меньшая величина экспериментальной добротности по сравнению с рассчитанной радиационной добротностью и значительно более слабая зависимость экспериментальной добротности от полярного индекса и от типа поляризации МШГ свидетельствует о том, что определяющий вклад в ширину линий в спектре вносит какой-то другой механизм уширения. Этот механизм приводит также к одинаковым значениям добротности для обеих поляризаций МШГ.

Существует несколько возможных механизмов, которые обуславливают уширение МШГ, распространяющихся в одной МСЧК. К числу таких механизмов относятся радиационные потери; рассеяние электромагнитной волны на шероховатостях поверхности и углеродных наноточках на поверхности МСЧК; рассеяние на неоднородностях плотности вещества МСЧК; поглощение в веществе МСЧК, в углеродных наноточках и в слое адсорбированных молекул на поверхности МСЧК [28]; неоднородное уширение за счет несферичности МСЧК [35]; однородное и неоднородное уширения, связанные с утечкой волн в подложку, на которой находится МСЧК [36].

Отсутствие информации о многих необходимых экспериментальных параметрах не позволяет достоверно оценить вклад каждого механизма уширения (кроме приведенного радиационного) в наблюдаемую экспериментально добротность МШГ. Мы полагаем, что значительный вклад могут вносить влияние несферичности МСЧК.

Если форма МСЧК отличается от сферической, то в первом приближении данные частицы можно рассматривать как сфероиды вращения с небольшой степенью эллиптичности. В таком сфероиде снимается вырождение МШГ по азимутальному индексу. При этом каждая МШГ с одним полярным индексом $l$ и радиальным индексом $q$, но с разным значением модуля азимутального индекса $(|m| \leq l)$ имеет свою собственную длину волны, зависящую от $m$, которая близка к длине волны МШГ для идеальной сферы с теми же $l$ и $q$. В результате, в спектре ФЛ вместо единственного пика, соответствующего МШГ идеальной сферы, возникает набор пиков с близкими длинами волн, соответствующих МШГ с разными индексами $m$. Перекрытие этих пиков приводит к неоднородному уширению пика ФЛ [37]. Следует отметить, что даже небольшое отклонение формы частиц от идеальной микросферы, которое трудно зарегистрировать экспериментально, приводит к неоднородному уширению МШГ [38].

Мы полагаем, что бо́льшая ширина пиков в спектре образца S61 (кривая 3, рис. 3) по сравнению с шириной пиков в спектрах образцов S60 и S59 (кривые 1 и 2, рис. 3), может быть объяснена уширением за счет возможной бо́льшей несферичности образца S61. Наблю- 
даемое отличие длин волн пиков в экспериментальном спектре и рассчитанных длин волн МШГ для образца S61 (кривая 3, рис. 3) также может быть объяснено этой причиной.

\section{4. Заключение}

В настоящей работе получены гибридные структуры из монодисперсных сферических частиц кремнезема, являющихся сферическими микрорезонаторами, и излучающих углеродных наноточек на их поверхности. Углеродные наноточки нанесены на поверхность МСЧК посредством контролируемой коагуляции в различных (аммиак, соляная кислота, глицерин) растворителях. Разработанные способы связывания УТ со сферическим микрорезонатором из МСЧК являются простыми и надежными методами создания гибридных структур, в которых реализовано взаимодействие электронных возбуждений в УТ и мод шепчущей галереи в микрорезонаторе, что приводит к усилению излучения УТ на длинах волн МШГ.

Изучены люминесцентные свойства гибридных структур и показано, что, изменяя длину волны возбуждения фотолюминесценции, возможно осуществить перекрытие широкого спектрального диапазона излучения от УФ до ближнего ИК. В спектрах ФЛ гибридных структур во всем диапазоне длин волн излучения УТ наблюдались интенсивные узкие пики, регистрируемые на фоне широкой полосы.

Методом матриц переноса сферических волн рассчитаны длины волн и добротности МШГ в исследованных сферических МР. Расчет позволил идентифицировать наблюдаемые узкие пики ФЛ как линии излучения УТ в МШГ. Определены поляризация, полярные и радиальные индексы наблюдаемых МШГ. Установлено, что добротность МШГ в экспериментальных спектрах ФЛ гибридных структур меньше рассчитанной радиационной добротности МШГ. Обсуждены возможные механизмы уменьшения добротности в гибридных структурах.

\section{Финансирование работы}

Работа выполнена с использованием средств госбюджета по теме госзадания 0040-2019-0012.

\section{Конфликт интересов}

Авторы заявляют, что у них нет конфликта интересов.

\section{Список литературы}

[1] S. Ganguly, P. Das, S. Banerjee, N.C. Das. Funct. Comp. Struct. 1, 022001 (2019).

[2] L. Cao, K.A.S. Fernando, W. Liang, A. Seilkop, L.M. Veca, Y.-P. Sun, C.E. Bunker. J. Appl. Phys. 125, 220903 (2019).
[3] K. Nekoueian, M. Amiri, M. Sillanpää, F. Marken, R. Boukherroub, S. Szunerits. Chem. Soc. Rev. 48, 4281 (2019).

[4] A. Sharma, J. Das. J. Nanobiotechnol. 17, 92 (2019).

[5] S. Baker, G. Baker. Angewandte Chem. Int. Ed. 49, 6726 (2010).

[6] O. Kargbo, Y. Jin, S.-N. Ding. Curr. Anal. Chem. 11, 4 (2015).

[7] F. Yan, Z. Sun, H. Zhang, X. Sun, Y. Jiang, Z. Bai. Microchim. Acta 186, 583 (2019).

[8] B. Möller, M.V. Artemyev, U. Woggon. Appl. Phys. Lett. 80, 3253 (2002).

[9] S. Götzinger, L. de S. Menezes, O. Benson, D.V. Talapin, N. Gaponik, H. Weller, A.L. Rogach, V. Sandoghdar. J. Opt. B: Quantum Semiclass. Opt. 6, 154 (2004).

[10] X. Fan, P. Palinginis, S. Lacey, H. Wang, M.C. Lonergan. Opt. Lett. 25, 1600 (2000).

[11] S.I. Shopova, G. Farca, A.T. Rosenberger. Appl. Phys. Lett. 85, 6101 (2004).

[12] C.E. Finlayson, P.J.A. Sazio, R. Sanchez-Martin, M. Bradley, T.A. Kelf, J.J. Baumberg. Semicond. Sci. Technol. 21, L21 (2006).

[13] D. Melnikau, D. Savateeva, A. Chuvilin, R. Hillenbrand, Y.P. Rakovich. Opt. Exp. 19, 22280 (2011).

[14] Y. Mi, Z. Zhang, L. Zhao, S. Zhang, J. Chen, Q. Ji, J. Shi, X. Zhou, R. Wang, J. Shi, W. Du, Z. Wu, X. Qiu, Q. Zhang, Y. Zhang, X. Liu. Small 13, 1701694 (2017).

[15] S. Schietinger, T. Schröder, O. Benson. Nano Lett. 8, 3911 (2008).

[16] S. Schietinger, O. Benson. J. Phys. B 42, 114001 (2009).

[17] J. Ward, O. Benson. Laser Photon. Rev. 5, 553 (2011).

[18] Y.P. Rakovich, J.F. Donegan. Laser Photon. Rev. 4, 179 (2010).

[19] F. Vollmer, L. Yang. Nanophoton. 1, 267 (2012).

[20] F. Vollmer, S. Arnold. Nature Meth. 5, 591 (2008).

[21] Е.Ю. Трофимова, А.Е. Алексенский, С.А. Грудинкин, И.В. Коркин, Д.А. Курдюков, В.Г. Голубев. Коллоидный журн. 73, 535 (2011).

[22] С.А. Грудинкин, Н.А. Феоктистов, Е.Ю. Трофимова, Д.А. Курдюков, К.В. Богданов, А.В. Баранов, А.В. Фёдоров, В.Г. Голубев. Письма в ЖТФ 39, (7) 51 (2013).

[23] Д.А. Курдюков, Д.А. Еуров, Е.Ю. Стовпяга, Д.А. Кириленко, С.В. Коняхин, А.В. Швидченко, В.Г. Голубев. ФТТ 58, 2454 (2016).

[24] D.A. Kurdyukov, D.A. Eurov, M.K. Rabchinskii, A.V. Shvidchenko, M.V. Baidakova, D.A. Kirilenko, S.V. Koniakhin, V.V. Shnitov, V.V. Sokolov, P.N. Brunkov, A.T. Dideikin, Y.M. Sgibnev, L.Yu. Mironov, D.A. Smirnov, A.Ya. Vul, V.G. Golubev. Nanoscale 10, 13223 (2018).

[25] E.Yu. Trofimova, D.A. Kurdyukov, S.A. Yakovlev, D.A. Kirilenko, Yu.A. Kukushkina, A.V. Nashchekin, A.A. Sitnikova, M.A. Yagovkina, V.G. Golubev. Nanotechnology 24, 155601 (2013).

[26] D.A. Kurdyukov, D.A. Eurov, D.A. Kirilenko, J.A. Kukushkina, V.V. Sokolov, M.A. Yagovkina, V.G. Golubev. Micro. Mesopor. Mater. 223, 225 (2016).

[27] Д.А. Еуров, Д.А. Курдюков, Е.Ю. Трофимова, С.А. Яковлев, Л.В. Шаронова, А.В. Швидченко, В.Г. Голубев. ФТТ 55, 1605 (2013).

[28] А.Н. Ораевский. Квантовая электрон. 32, 377 (2002).

[29] М.Л. Городецкий. Оптические микрорезонаторы с гигантской добротностью. Физматлит, М. (2011). 416 с.

[30] J.M.M. Hall, T. Reynolds, M.R. Henderson, N. Riesen, T.M. Monro, V. Shahraam Afshar. Opt. Exp. 25, 6192 (2017).

[31] I.H. Malitson. J. Opt. Soc. Am. 55, 1205 (1965). 
[32] S.A. Grudinkin, N.A. Feoktistov, M.A. Baranov, A.N. Smirnov, V.Yu. Davydov, V.G. Golubev. Nanotechnology 27, 395606 (2016).

[33] D.K. Nelson, B.S. Razbirin, A.N. Starukhin, D.A. Eurov, D.A. Kurdyukov, E.Yu. Stovpiaga, V.G. Golubev. Opt. Mater. 59, 28 (2016).

[34] A.M. Beltaos, A. Meldrum. J. Lumin. 126, 607 (2007).

[35] H.M. Lai, P.T. Leung, K. Young, P.W. Barber, S.C. Hill, Phys. Rev. A 41, 5187 (1990).

[36] H. Ishikawa, H. Tamaru, K. Miyano. J. Opt. Soc. Am. A 17, 802 (2000).

[37] M. Gerlach, Y.P. Rakovich, J.F. Donegan. Opt. Exp. 15, 3597 (2007).

[38] N. Riesen, T. Reynolds, A. Francois, M.R. Henderson, T.M. Monro, Opt. Exp. 23, 28896 (2015).

Редактор К.В. Емцев 